\title{
VOLATILIDAD DE LAS ECONOMÍAS INDUSTRALIZADAS Y SU IMPACTO EN LAS ECONOMÍAS LATINOMERICANAS: 2008-2010
}

\section{VOLATILITY OF THE INDUSTRIALIZED ECONOMIES END AND THEIR IMPACT ON LATIN AMERICAN ECONOMIES: 20082010}

\author{
Nicko Gomero Gonzáles* \\ Docente Asociado de la Facultad de Ciencias Contables, UNMSM \\ Ana María Gutiérrez Huby ${ }^{* *}$ \\ Docente Principal de la Facultad de Ciencias Contables, UNMSM
}

[Recepción: Agosto de 2010/ Conformidad: Setiembre de 2010]

\section{RESUMEN}

Los gobiernos de los países en crisis, especialmente los de las economías avanzadas, parecen haber entendido que la asignación de los recursos no se pueden dejar a las leyes del mercado, tal como argumentaban los neoclásicos del liberalismo, que en sí es la fuente filosófica del proceso de globalización. La intervención en la economía a costa de incurrir en elevados déficit públicos, en cierta forma ha contribuido que la recesión no se profundice más a nivel global.

La fuerte recesión creo escenarios de vulnerabilidad en las economías avanzadas, tales como en el sector financiero y laboral, que se tradujo en el cierre de bancos y la pérdida de confianza del consumidor. En Norteamérica el gasto de consuno privado llega a los 6 billones de dólares, sólo la contracción de un $20 \%$ de esta variable representaría una merma importante de los países latinoamericanos que llegan a este mercado con su producto de exportación.

Estos resultados dan una lectura de dependencia de las economías latinoamericanas a las volatilidades de las economías industrializadas, países cuyas volatilidades, inmediatamente son transmitidas a las economías

\begin{abstract}
Governments of countries in crisis, especially in advanced economies seem to understand that the allocation of resources can not be left to market forces as the neo-classical liberalism argued that itself is the philosophical source of the process globalization. The intervention in the economy at the expense of incurring high deficit in some way contributed to the deepening recession is not more global.

I think the severe recession scenarios of vulnerability in the advanced economies, such as in the financial sector and labor, which resulted in the closure of bank s loss of consumer confidence. Only North America together private spending reaches $\$ 6$ billion, the contraction only $20 \%$ of this variable would represent a significant decline in Latin American countries that reach this market with its export.

These results give a reading of dependency on Latin American economies to the volatility of the industrialized economies, countries whose volatility is immediately transmitted to the peripheral economies. The sensitivity of industrial economies has led to recede in their macroeconomic accounts, but conti-
\end{abstract}

* Doctor en Ciencias Económicas. Docente de la Unidad de Postgrado y Docente Asociado de la Facultad de Ciencias Contables, UNMSM. E-mail: nickgo_6@msn.com, gomero_econ@yahoo.es

** Magíster en Administración y Licenciado en Administración, UNMSM. Jefe de la Oficina de Calidad Académica y Acreditación de la Facultad de Ciencias Contables. E-mail: anamaria_0105@hotmail.com 
periféricas. La sensibilidad de las economías industriales ha originado que retrocedan en sus cuentas macroeconómicas, pero continúan liderando la economía global, especialmente Estados Unidos, cuyo aporte del PBI global llega en promedio al $23 \%$, dada esta supremacía económica, los hilos financieros y económicos estarán al mando de este país, por lo que las economías latinoamericanas deberán ajustarse a su política global. Ya no existe duda de que en Estados Unidos, la tasa de desempleo se acercará al 10\%, pero siempre primará su poder económico. Es por ello que por cualquier volatilización de esta economía, conjuntamente con los G20 o G7, la región se vería vulnerada.

La simetría entre las economías avanzadas y las que están en vías de desarrollo se aprecia en todos los campos, financiero y económico hasta político, pero esto no implica que esta región avance paralelamente en su cuentas macroeconómicas, tal como lo hace China e India, de mantenerse esta tendencia, estos dos últimos países, conjuntamente con otros emergentes llegarían a dominar la economía mundial, con un PBI que superaría a las economías del primer mundo.

Pero hay duda, que los ingresos en el primer mundo están mejor redistribuidos, con empresas, cuyas utilidades rebasan largamente el PBI de algunos países pobres, esta asimetría es producto de la alta concentración de la riqueza que se observa a nivel global.

El FMI argumenta que el proceso de recuperación económica está en camino y que las economías exportadoras de materias primas se verán beneficiadas, esta posición del Fondo Monetario es la más clara evidencia que las economías latinoamericanas, para estar bien, tienen que esperar que los países industrializados tengan buenos resultados económicos, teoría de la dependencia no señalada explícitamente por este organismo mundial. No hay duda que, si la economía global avanza, conjuntamente con China, India y Rusia, los países exportadores de materias primas tendrían en azul sus cuentas externas, pero a la vez seguirán siendo economías que solo viven de sus ventajas comparativas, escenario de total inestabilidad.

Es cierto que los países latinoamericanos han tenido un leve desenganche de las economías del primer mundo, pero aun es fuerte la correlación que existe entre el mundo avanza- nued to lead the global economy, especially the United States whose contribution to global GDP on average reaches $23 \%$, given this economic supremacy, financial and economic threads will be in charge of this country, so the Latin economies should adjust to global politics. Since there is no doubt that the United States, the unemployment rate approaches $10 \%$, but always trump economic power. That is why any volatilization of this economy, together with the G20 and $\mathrm{G} 7$, the region would be violated.

The symmetry between the advanced economies and those that are developing can be seen in all fields, financial and economic to political, but this does not imply that this region parallel progress in macroeconomic accounts, as does China and India that this trend continues, the latter two countries, along with other emerging economies come to dominate the world with a GDP would overtake the economies of developed countries.

But no doubt that the revenue in the first world are better redistributed to companies whose earnings exceed the GDP largely poorer countries, this asymmetry is caused by the high concentration of wealth that is observed globally.

The IMF argues that the economic recovery is underway and that the commodity-exporting economies will benefit, this position of the IMF is the clearest evidence that Latin American economies has to be well expected that industrialized countries have good economic performance, dependency theory does not explicitly indicated by this world body.

There is no doubt that if the global economy advances, together with China, India and Russia, the raw material exporting countries in blue have their external accounts, but both economies will continue to live only on their comparative advantages, the scene of total instability.

It is true that Latin American countries has had a slight release of the first world economies, yet there is a strong correlation between the advanced world and the region, which is why in 2009, which was the year where you felt greater global crisis, all Latin American countries experienced declines in their economic growth, except Peru, which had a slight growth below $1 \%$. 
do y la región, es por ello que en el 2009, que fue el año donde se sintió con mayor grado la crisis global, todos los países latinoamericanos experimentaron descenso en sus crecimiento económico, excepto Perú, que tuvo un leve crecimiento por debajo del $1 \%$.

Por último, cabe señalar que las asimetrías en el sector financiero y económico son una característica de la economía global, donde los países avanzados tienen la posibilidad de realizar operaciones de salvataje equivalente a 4 veces el PBI de una economía en desarrollo y además se dan la licencia de salvar bancos en quiebra bajo el pretexto de evitar el colapso de la economía global, cuando sabemos que la corrección a estos desfases, pasa por aplicar políticas estructurales y de tipo global, donde las asimetrías dejen de crear mayores espacios de vulnerabilidad.

Palabras clave: Economías avanzadas, economías industrializadas, volatilidad de las economías, Economías de América Latina.

\section{OBJETIVO GENERAL}

El trabajo de investigación se plantea como objetivo demostrar el grado de interdependencia que existe entre las principales economías del mundo y las economías latinoamericanas, así como las asimetrías económicas y financieras que se vienen presentando entre ambos bloques económicos, bajo el proceso de globalización.

\section{INTRODUCCIÓN}

Si bien un país tiene la potestad de diseñar e implementar su política económica, pero esta no puede estar totalmente alejadas, de los nuevos paradigmas mundiales, tal como es el proceso de globalización y operativizada a través de la apertura de los mercados. Los tratados de libre comercio son el mejor ejemplo de cómo los gobiernos vienen apostando para lograr mejores niveles de crecimiento económico dentro de este mundo globalizado. Al formalizar la interconexión
Finally it should be noted that asymmetries in the financial sector and economic development is a feature of the global economy, where the 'advanced countries have the possibility of salvage operations equivalent to 4 times the GDP of a developing economy and also give license to save failing banks under the pretext of preventing the collapse of the global economy when we know that the correction of these gaps, passes through structural policies and global nature, where the asymmetries stop creating more room for vulnerability.

Key words: Advanced economies, industrialized economies, Volatility of the industrialized economies, Latin American economies.

económica, muchas veces no importa si existe o no ventajas comparativas, si se posee o no mejores posiciones competitivas; la esfera política, quienes son los encargados de instrumentar esta relación de comercio, solo centra su confianza en las leyes del mercado para optimizar la asignación de los recursos productivos. Este caso se está presentando en casi todos los países de la región, salvo en aquellas economías cuyas políticas públicas están direccionadas por un modelo participativo del Estado.

La globalización, apoyada por la tecnología de la información ha generado el potenciamiento del mercado real y financiero, pero también se ha creado bolsones de riqueza producto únicamente de posiciones especulativas de inversionistas cortoplacistas que centran su accionar en los mercados, bajo los pilares filosóficos del mercantilismo. El fortalecimiento del mercado de derivados, donde la mayoría de las veces solo se negocian contratos, es el mejor ejemplo de las burbujas financieras creadas por las operaciones espe- 
culativas que luego terminan por desencadenar escenarios de crisis, tal como lo sucedido en el 2008, cuyo contagio al sector real fue realmente catastrófico, comprometiendo inclusive los regímenes de gobierno.

Como ya se señaló, la filosofía de la globalización, viene guiando los programas de gobierno de muchos países, creyentes de las fuerzas del mercado, echan mano a las corrientes doctrinarias de las teorías neoclásicas liberales que en sí representan las líneas de referencia para la globalización. Las fuerzas del mercado, según esta corriente económica, deben ser las orientadoras en la asignación eficiente de los recursos económicos.

Si la optimización y los equilibrios son los objetivos de la globalización, entonces ¿por qué se generan asimetrías económicas y sociales? ¿por qué se dan las concentraciones de riqueza en el mundo, por qué las crisis especulativas? ¿por qué los derrumbes financieros? ¿por qué las masas de trabajadores sin posibilidad de encontrar un empleo? Ylo que es peor, ¿por qué en el mundo existen más de mil millones de personas que viven con un dólar por día? ¿Todo esto es lo que persigue la globalización? Definitivamente no, como cualquier modelo de desarrollo, sus líneas maestras apuntan al desarrollo de la humanidad, pero por las cifras que más adelante se analizarán, pareciera que es todo lo contrario ya que las asimetrías se están profundizando, lo cual resulta peligroso para la estabilidad mundial.

Esta característica del mercado mundial está conllevando a que se profundice su volatilización, cada vez los indicadores de crecimiento económico en los países del prime primer mundo son más débiles y menos estables. Por otro lado, se está formando un sector financiero que incluye el mercado monetario y de capitales a la orden de los grandes especuladores cortoplacistas, que luego terminan por abrir nuevas brechas de inestabilidad a los modelos económicos. Este grado de sensibilidad transciende a las economías latinoamericanas, que como se sabe, están ancladas en los vaivenes del mercado internacional. especialmente aquellos países que basan sus economías a las ventajas corporativas que poseen en el sector exportador de commodities.

\section{METODOLOGÍA}

El estudio de investigación es de tipo APLICATIVO porque los resultados obtenidos, los cuales serán recomendados, deben ser aplicados para resolver los problemas de volatilización de los mercados y lo grados se asimetrías que se vienen desarrollando bajo el proceso de globalización, con lo cual se crearía un mejor escenario para el desenvolviendo de los agentes productivos. Asimismo es de tipo exploratoria y correlacional, ya que en el estudio se llega a explorar los fenómenos económicos donde se encuentran variables económicas de carácter dependiente e independiente, con lo cual se le da además, el carácter de explicativo.

Para la realización del trabajo de investigación se utilizó información secundaria, para ello se recurrió a fuentes bibliográficas del FMI, Banco Mundial, Naciones Unidas, Banco Central de Reserva de Perú, Reserva Federal. La calidad de la información garantiza la seriedad del estudio, materia del proyecto presentado.

\section{COMPORTAMIENTO DE LA ECONOMÍA GLOBAL: PAÍSES INDUATRIALIZADOS}

La economía mundial, bajo el nuevo paradigma de la globalización, si bien es cierto ha potenciado a la actividad económica y finan- 
ciera de muchos países, pero a la vez sigue dando señales de debilidades que se vienen traduciendo en la creación de escenarios de alta volatilidad y riesgo. El crecimiento económico sostenido ha dejado de ser una meta de fácil alcance dentro de los programas de gobierno, este se ha sustituido por querer lograr indicadores que siquiera den señales de una lenta reactivación económica, situación que se viene presentando especialmente en las principales economías del mundo. $\mathrm{Al}$ margen quedan China e India, en cuya sostenibilidad económica, gracias a los efectos multiplicadores que viene ejerciendo la intervención gubernamental, su tasa de crecimiento del PBI es en promedio 5 veces de lo que podrían lograr los países que aun mantiene la hegemonía económica mundial, en especial Estados Unidos de Norteamérica.

Si bien la crisis global experimentada en el 2008, cuyos efectos aún siguen latentes en el campo real y financiero, ha golpeado significativamente a la economía norteamericana, pero a pesar de ello su cuota de participación en la formación del PBI global sigue por el $23 \%$, cifra que a todas luces se traduce en el mejor mercado para que los países emergentes latinoamericanos aumenten sus ingresos de divisas por exportación.

La supremacía de Estados Unidos en la economía global no solo se puede medir por su grado de aporte a la formación del PBI, sino también por el alto grado de consumo que se experimenta en ese país, que según la revista World Watch (Perspectiva Mundial), está representada por 242 millones personas, que sí se considera a la sociedad consumidora europea, el dinamismo de estos dos mega mercados, llega a las 591 millones de personas, situación que se fundamenta en un ingreso per cápita que en promedio supera los US\$ 50 mil, con excepción de Luxemburgo que sobrepasa los US\$ 113 mil.
Es innegable que las cifras presentadas para el mundo occidental o países industrializados, que según Worl Watch llega a los 816 millones de consumidores representa una oportunidad para los países latinoamericanos para fortalecer sus industrias de exportación, pero también es preciso señalar que dado los ciclos económicos desfavorables, estas se pueden convertir en un riesgo para estas economías, debido al hecho que, el comportamiento de sus principales variables macroeconómicas tales como las fiscales, monetarias y cambiarias están altamente correlacionadas a eventos de coyuntura internacional. El efecto transmisión, por el efecto anclaje que existe con las economías industrializadas, no solo se queda en las variables macros o microeconómicas, sino también llega al ámbito laboral, pudiéndose crear escenarios desfavorables tales como lo ocurrido en la última crisis global.

Las economías industrializadas, cuyos modelos económicos se asientan bajo las bases filosóficas de la globalización, con la última crisis han dado más que muestras de su alto grado de vulnerabilidad, hecho que se puede sustentar utilizando las cifras del FMI y que está representada en el Gráfico $\mathrm{N}^{\circ} 1$. Las caídas productivas se visualizan en todas las potencias económicas: la Zona del Euro, Estados Unidos, Japón, Reino Unido, el cual se tradujo en una caída del PBI mundial del $-0.6 \%$. Estos resultados negativos se plasmó además en el deterioro de la demanda agregada, debilitándose el consumo y las inversiones, brecha que fue asumida por los respectivos gobiernos a fin de que la actividad productiva no caiga a niveles de estancamiento o depresión.

Estas cifras además corroboran la interdependencia de los mercados, característica del proceso de globalización. Cuanto más interrelacionados estén las economías, cual- 
Gráfico N. ${ }^{\circ} 1$

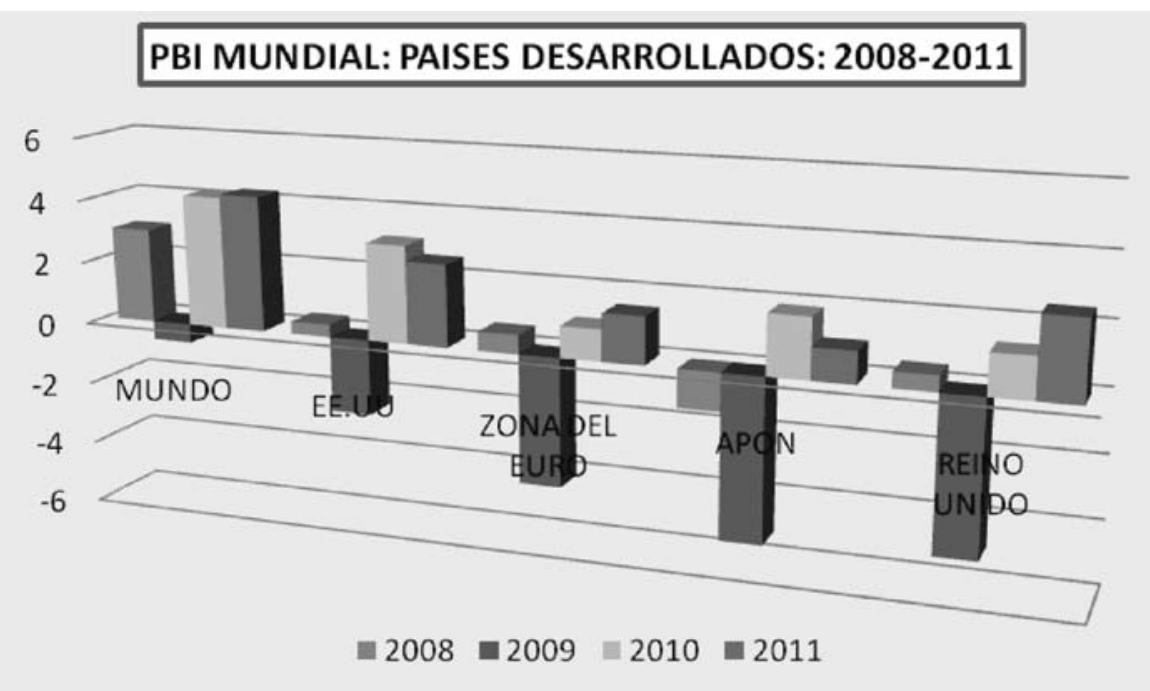

Fuente: Fondo Monetario Internacional (FMI)

quier síntoma de crisis, se puede transformar en una "pandemia económica global". Con esto no se quiere decir que los países atomicen sus economías, todo lo contrario, es necesario fortalecer los lazos comerciales, hasta políticos. Pero sí es necesario afirmar que, bajo estos escenarios, es indispensable que los agentes económicos tomen conciencia que no se puede tomar posturas especulativas ya que estas operaciones terminan por volatilizar los mercados.

El caso de la crisis en los PIIG( Portugal, Irlanda, Italia y Grecia) es la última evidencia de la volatilidad de los mercados, el efecto arrastre no solo llegó a los índices bursátiles sino que también golpeó duramente la sostenibilidad del Euro en el mercado de divisas. Para evitar nuevamente la propagación de una crisis global, el FMI y la Unión Europea se vieron forzados en otorgar un paquete de ayuda a Grecia que ascendió a US\$110 mil millones, bajo el compromiso de que ese gobierno se comprometa a realizar severos ajustes fiscales, como es el recorte de los salarios de la burocracia estatal hasta en un $20 \%$, ahorro público que le permitiría pagar su deuda externa, que llega a los 270 mil millones de euros. Los ajustes de este tipo, como es ca- racterístico, terminaron por convulsionar su escenario social. Los analistas están considerando que este país caerá en incumplimiento de pagos y que de ser así, volatilizará el mercado europeo y con ellos los demás mercados correlacionados.

La volatilidad de los mercados ha puesto de moda las "operaciones de rescate". Ahora no solo de bancos, sino de gobiernos, dado el hecho, que si Portugal, España e Irlanda ven profundizado sus crisis económicas el colchón de salvataje debe de llegar en promedio a los 600 mil millones de euros. Todo este movimiento de dinero, que muchas veces no logra el efecto deseado, hace pensar que en el mundo existe más de1000 millones de personas que viven por debajo de la línea de pobreza y que su supervivencia lo sostienen con menos de US\$ 1 por día. ¡Qué gran asimetría global ${ }_{i}$

Bajo este escenario de convulsiones no hay que perder de vista a España, como una de las principales economías de Europa, cuya tasa de crecimiento para el 2010, según el FMI, seguirá siendo negativa $(-0.4 \%)$. Este país, dicho sea de paso, ostenta la más alta tasa de desempleo el cual llega al 19.4\% 
Quizás los expertos puedan opinar que la solución esta crisis pasa por tomar medidas monetarias a nivel de la región, pero estas posturas han demostrado que solo son medidas cortoplacistas y que no van a lo profundo de la crisis global, es por ello que las oleadas de inestabilidades se seguirán presentando con mayores síntomas perniciosos y en menores espacios de tiempo.

Lo realizado por la FED para atenuar la crisis global es la más clara señal de cómo las medidas de coyuntura no ayudan a dar soluciones estructurales. Cabe recordar que, bajo una política de "ayuda humanitaria", a los grandes especuladores. El Banco Central Norteamericano se vio obligado a rescatar a las dos más importantes entidades hipotecarias norteamericanas: Fannie Mae (Asociación Federal de Hipotecas Nacionales) y Freddie Mac (Corporación Federal de Préstamos Hipotecarios para la Vivienda). Esta, ha sido considerada la mayor nacionalización de la historia, con un costo fiscal cerca de 200 mil millones de dólares. A este escenario de crisis cabe agregar lo señalado por la Corporación Federal de Garantía de Depósitos (FDIC), que informaba en el 2009 la quiebra de 53 en Estados Unidos.

Esta información corrobora que las ayudas financieras de Obama, la cual llegó a los US\$ 787 mil millones, no logró estabilizar los mercados. Si el sector monetario seguía volatilizado, de igual forma lo hacían los mercados bursátiles, centrados no solo en el mercado de capitales norteamericanos, sino también en toda la zona del euro y Asia, donde los índices bursátiles tuvieron retrocesos importantes, tales como el IBEX. NASDAQ, DOWJONES, S\&P.

Como se dice en economía, no hay "lonche gratis", ante estos flujos de dinero han creado un forado fiscal casi inmanejable, ha inducido que el gobierno americano opte por aplicar un ajuste fiscal, que sería uno de los más duros que se haya experimentado en los últimos 40 años, el cual le quitaría dinámica del PBI en un 0,09\%.

Estos actos de intervención gubernamental son políticas totalmente ajenas al modelo neoliberal impulsado ideológicamente por Milton Fridman y se acerca más a los preceptos teóricos del keynesianismo a ultranza. El modelo liberal deja otra vez huellas de vulnerabilidad filosófica y operativa, por ello que extiende sus manos para rescatar instrumentos que eran fuertemente criticados por los pensadores neoclásicos del liberalismo.

La volatilidad de las principales economías no solo comprometió a su frente interno, sino que los efectos se fueron irradiando a economías periféricas como las latinoamericanas, experimentándose caídas sostenidas de las exportaciones de materias primas, derrumbe de las bolsas, debilitamiento de la presión tributaria, desempleo, en otros efectos, con lo cual se ponía en evidencia el fortalecimiento de los eslabones económicos en escenarios de globalización.

\section{La crísis y los mercados bursátiles de las principales economías del mundo}

La crisis observada en el mercado real, se centró en los mercados bursátiles, que según algunos analistas lo consideran como el principal termómetro del avance de una economía. La volatilidad de las principales Bolsas del Mundo se tradujo en grandes descapitalizaciones de empresas que eran como las representativas a nivel global, estas estaban preferente focalizadas en la industria automotriz como es GM, Chrysler. De igual forma empresas tecnológicas, se servicios e industriales que cotizan en las Bolsas Globales experimentaron fuertes caídas en sus acciones lo cual indujo a su desvalorización y al deterioro de capitales 
especulativos que habían buscado refugio en estos activos financieros.

Aparte de rescatar activos tóxicos y realizar salvamentos financieros a gran escala, la FED, bajo el objetivo de estabilizar los mercados bursátiles decidió bajar la tasa de referencia en una banda del mecanismo monetario que no logro su resultados deseados ya que los indicadores reales y financieros se seguían deteriorando, tal como se puede apreciar en el grafico $\mathrm{N} .{ }^{\circ} 2$, donde se aprecia la caída sostenida de dos del Dow Jones (Estados Unidos) y el IBEX en España.

No hay señales claras sobre el despegue sostenido de las bolsas Globales, peor aún, la situación bursátil no puede ser tan alentadora ante los anuncios de la Reserva Federal sobre nuevos retrocesos de la producción para los años 2011 y 2012, que en definitiva comprometería con mayor fuerza los mercados globales.

\section{Concentración de la Riqueza Global: un Problema de Asimetría}

Como se ha mencionado en la identificación del problema, la globalización se ha convertido en un instrumento para amasar y fortalecer grandes fortunas. Y también para profundizar escenarios de pobreza de muchas economías, que solo dependen de los exportación de productos sin ningún valor agregado. En los últimos 20 años, tras muchas volatilidades económicas y financieras los capitales especulativos de tipo personal han llegado inclusive a superar a cifras que rebasan el PBI de muchos países. Paralelamente en esta sociedad global se localizan aquellos excluidos que superan los mil millones de habitantes que no obtiene beneficio alguno de los nuevos modelos económicos. Estos excluidos representan casi el 17\% de la población mundial.

Los datos que se presentan a continuación demuestran las grandes asimetrías económicas globales. En el país más rico del mundo como es Estados Unidos, y si será por muchos años, existen tres personas como son -Bill Gates, Paul Allen y Warren Buffett- cuya fortuna logra superar el PBI de 42 naciones pobres, en las cuales viven 600 millones de habitantes. Es más, en el mundo existen 356 personas que ostentan una riqueza que supera a la renta anual del $40 \%$ de la humanidad".

Se comenta que China podría superar los niveles de riqueza que se maneja en Norteamérica, pero las cifras de ingresos que posen ambos países muestran una diferencia abis-

Grafico. $\mathbf{N}^{\circ}$ 2: Comportamiento del Dow Jones

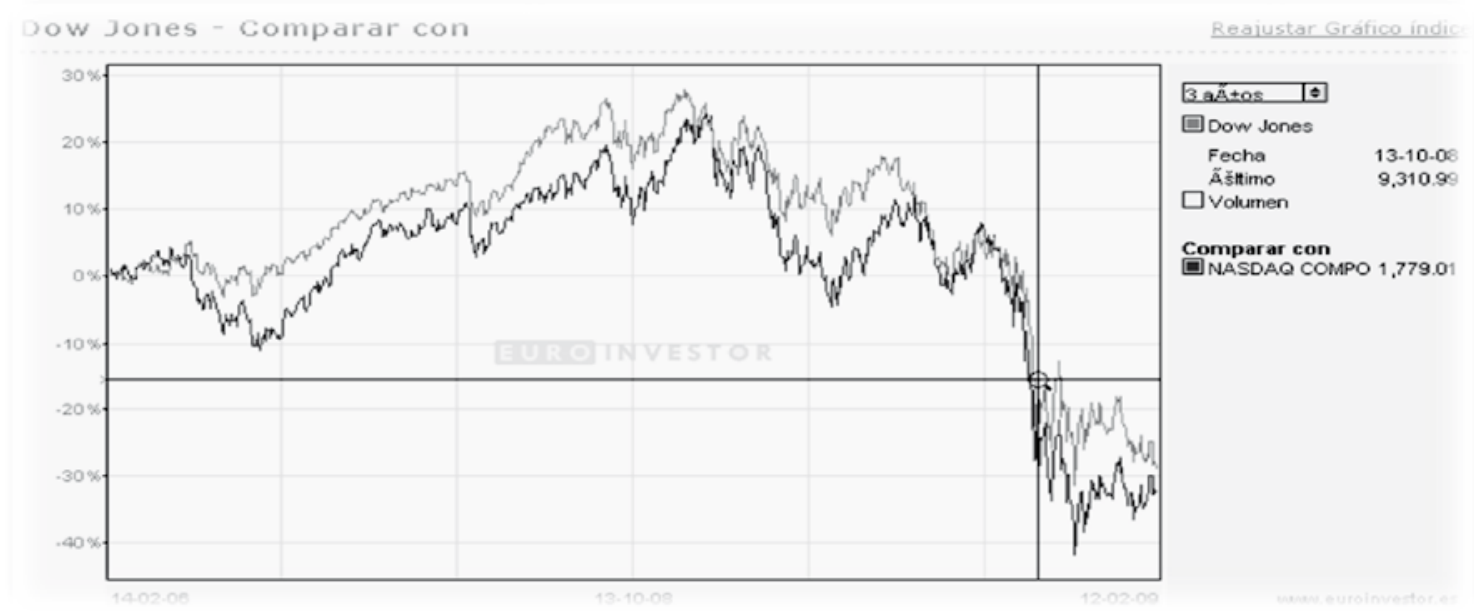

Fuente: bolsmania. Finanzas.com 
mal. En este primer país, el PBI per cápita no llega a los US\$ 4000, mientras en Estados Unidos supera los US\$ 40 mil. Ahora si se mide el avance social de ambos países por el tipo de redistribución de la riqueza también se encuentra diferencias sustanciales y estructurales, que demuestran que a China todavía le queda mucho camino que recorrer para ser tipificado como un país del primer mundo, afirmación que se puede demostrar con la siguiente información aparecida en Gestión, principal medio económico de Perú: "143 mil personas ganan más de 10 millones de yuanes en Beingin. 204 millones viven con 1.25 dólares al día. 8800 persona poseen activos por 100 millones de Yuanes. 86 millones de Yuanes es lo que cuesta los sobornos al año. En todo este país los incidentes en masa, como huelgas, manifestaciones, choques étnicos, aumentó a 90 mil en el 2009, 20 mil más que el 2007. Lo que es más grave, un obrero chino gana en promedio mensual US\$ 70". Como se puede apreciar, en la China a pesar de su despegue económico, los bolsones de excluidos los tendría que llevar a repensar su modelo de política social, de lo contrario a largo plazo podría caer en escenarios de insostenibilidad social, que comprometería gravemente su sistema político.

La Organización de las Naciones Unidas (ONU) elaboró una investigación que evidencia cómo se divide la riqueza en el mundo. Los datos son impactantes ya que, por ejemplo, el $2 \%$ de la población más rica tiene más de la mitad de la riqueza del mundo. Otro estudio señala que América del Norte acumula el 34\% de la riqueza global, Europa concentra el 30\% y algunos países de altos ingresos de Asia y el Pacífico (como por ejemplo Australia y Japón) poseen el $24 \%$ de la riqueza total. En síntesis, la riqueza está altamente concentrada en estas tres regiones del mundo que acumulan en su conjunto el
$90 \%$ de la riqueza global. La proyección de esta tendencia para el 2025 haría prever 2 mil millones de personas en el mundo. . Esta asimetría entre persona y países tenderán a ensancharse si es que los gobiernos de los países industrializados siguen protegiendo a sus más grandes especuladores, utilizando para ello el argumento se salvar a su país de la crisis global.

Como se sabe para entrar a formar parte de la lista de los hombres más ricos del mundo de Forbes, hay que tener un patrimonio mínimo de 1.000 millones de dólares, bajo este parámetro la lista de los hombres más ricos la conforman 1.011 personas, con una fortuna total de 3,6 billones de dólares.

Así como la globalización ha creado grandes riquezas personales, también ha fortalecido la posición de empresas multinacionales, cuyo nivel de capitalización se ha incrementado en forma exponencial, siendo las 10 más importantes del mundo las que señalan a continuación. La revista Forbes las clasifica de la siguiente manera para el 2010:

1. Google (valorada en 100,000 millones de dólares). Google Inc. es la empresa propietaria de la marca Google, cuyo principal producto es el motor de búsqueda del mismo nombre. Fue fundada el 7 de septiembre de 1998 por Larry Page y Sergey Brin.

2. Microsoft (valorada en 76,249 millones de dólares). Empresa multinacional estadounidense, fundada en 1975 por Bill Gates y Paul Allen. Dedicada al sector de la informática, con sede en Redmond, Washington, Estados Unidos; desarrolla, fabrica, licencia y produce software y equipos electrónicos.

3. Coca-Cola (valorada en 67,625 millones de dólares). Coca-Cola es un refresco carbonatado vendido en tiendas, restaurantes y máquinas expendedoras en más de 200 países. Es producido por The Coca-Cola Company. 


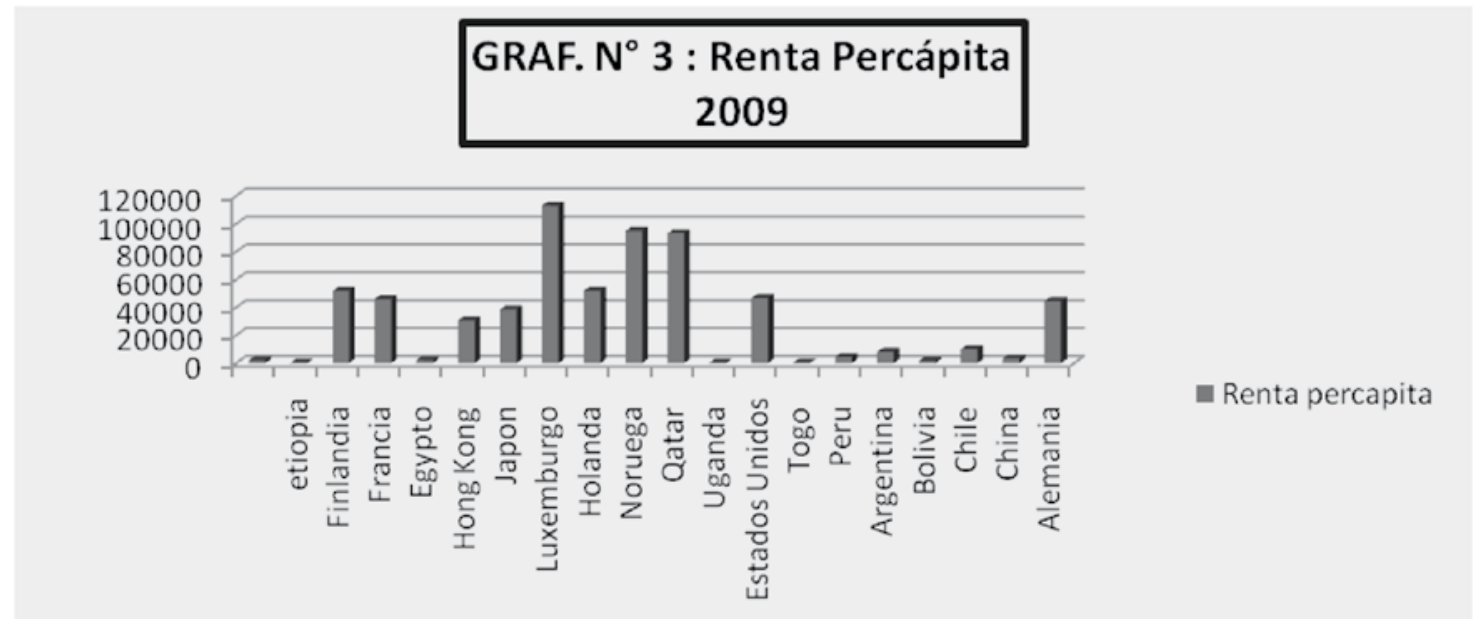

Fuente: FMI . Elaboración propia

4. IBM (valorada en 66,622 millones de dólares). International Business Machines (IBM), conocida coloquialmente como el "Gigante Azul", es una empresa multinacional que fabrica y comercializa herramientas, programas y servicios relacionados con la informática.

5. McDonald's (valorada en 66,575 millones de dólares). Cadena de restaurantes de comida rápida.

6. Apple (valorada en 63,113 millones de dólares). Empresa multinacional estadounidense que diseña y produce equipos electrónicos y software.

7. China Mobile (valorada en $62,283 \mathrm{mi}-$ llones de dólares). También conocida como China Mobile o CMCC, es el mayor operador de telefonía móvil de China y del mundo por cantidad de clientes. Su red está basada en el estándar europeo GSM.

8. General Electric (valorada en 59,793 millones de dólares). Con sede central en Fairfield, Estados Unidos, es una empresa multinacional de infraestructuras, servicios financieros y medios de comunicación altamente diversificada: desde energía, agua, transporte y salud hasta servicios de financiamiento e información.
9. Vodafone (valorada en 53,727 millones de dólares). Operador de telefonía móvil, fija y de ADSL; multinacional con sede central en Newbury, Berkshire, Reino Unido.

10. Marlboro (valorada en 49,460 millones de dólares). Marca de cigarrillos hecha por Philip Morris creada a principios de 1953, y anunciado originalmente como un tabaco para personas ligadas al western. Su nombre proviene de la calle Great Marlborough, en Nueva Jersey, donde se localizaba originalmente la fábrica

Como se puede observar, el nivel de riqueza de las empresas más poderosas del mundo, que en su mayoría están en el sector tecnológico, siguen sólidas patrimonialmente, sus niveles de venta están en constante crecimiento, cuyo volumen está muy por encima del PBI de países latinoamericanos y africanos, tal como se muestra en el gráfico $\mathrm{N}^{\circ}$ 3. El grado de participación de estas empresas no solo se centran en el campo productivo, sino que sus hilos de poder trasvasan el ámbito financiero hasta llegar al político y son las grandes responsables de la contaminación ambiental. 
GRAF. $N^{\circ} 4$ : INGRESO DE PRINCIPALES EMPRESAS GLOBALES Y PBI DE ECONOMIASEMERGENTES: 2010

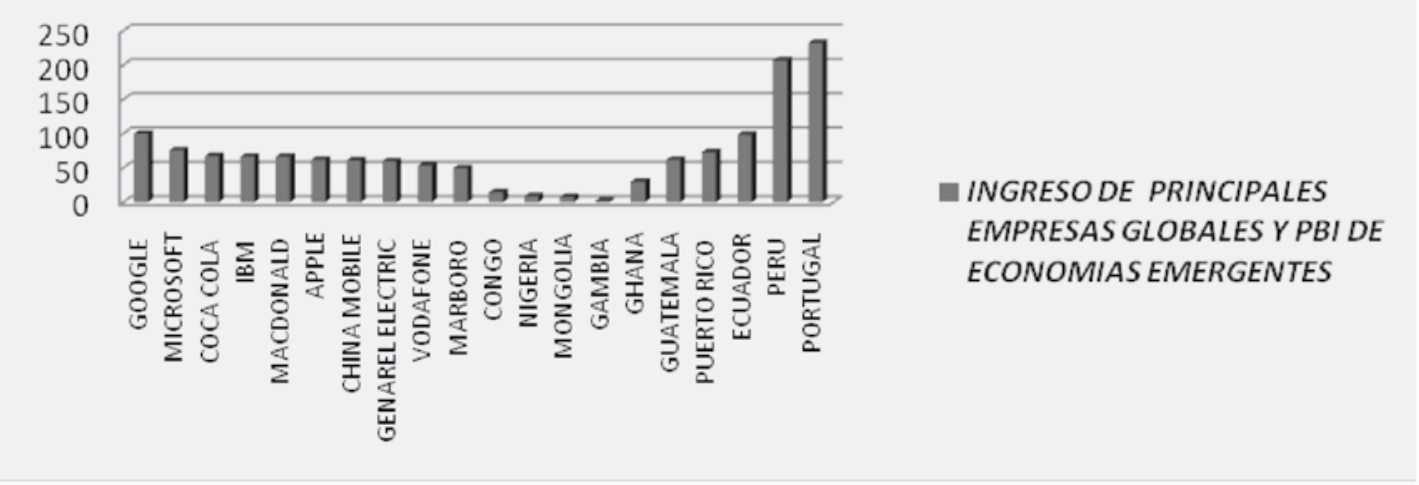

Fuente: FMI. Finanzas.Com. Forbes.

Elaboración propia

Tal como ya se ha demostrado, la crisis financiera internacional desatada en Estados Unidos sigue originando serios desequilibrios económicos a nivel global, bajo la actual coyuntura no está en juego la solidez o fragilidad económica de un país en forma unilateral, si no está de por medio la estabilidad de toda la economía del mundo, es por ello que es necesario que los gobiernos diseñen políticas de carácter monetario o fiscal para salir de este entrampamiento pero cuyas repercusiones sean de carácter globalizado.

Dada la sistematización de los mercados, cuando un fenómeno económico llega a magnificarse, los efectos colaterales son inmediatos, es por ello que los desequilibrios macroeconómicos van a afectar a las variables macrosociales, siendo una de ellas y quizás la más relevante el desempleo. El grado de importancia radica en el hecho que si una persona pierde su puesto de trabajo dejará de percibir un ingreso, y si el Estado no aplica políticas de subsidio, desmejorará su calidad de vida y también la de su familia. Si el Estado de paro es persistente, los niveles de pobreza pasarían a elevarse automáticamente, esto podría generar escenarios de convulsión social y graves problemas a la gobernabilidad.
El desempleo, el cual es un derivado de lo que está pasando en la economía real, se está presentando en todas las economías de Europa, siendo los resultados una clara muestra de la vulnerabilidad de la Economía de Mercado, cuyo modelo era aplicado por todos los países occidentales y cuyos principios filosóficos dieron soporte al proceso de globalización, que ahora viene generado desempleos en cadena en todas las economías afectadas por la crisis global.

$\mathrm{Y}$ ¿qué hay sobre el plano laboral en Europa como producto de la volatilidad de los mercados? Como era de esperarse, en el epicentro de la crisis, Norteamérica, en el mes de noviembre del 2008, la tasa de desempleo ya llegaba al 6,7\%, el nivel más alto después de 15 años. La pérdida de empleos afectó a fábricas, compañías de construcción, firmas financieras, minoristas y varias ramas de la economía, incluyendo el turismo. Estos resultados comprometerán aún más al mercado financiero de Estados Unidos, debido a que importante cantidad de deudores estaría en insolvencia para cumplir con sus obligaciones bancarias, con lo cual estas instituciones se verían en problemas para equilibrar sus cuentas financieras. 
Para el 2010, el escenario de crisis social no ha cambiado en nada, las empresas siguen recortando horas de trabajo, se siguen cerrando empleos y si se crean están muy por debajo de las expectativas gubernamentales, resultados que ha conllevado a estimar que para finales del 2010 la tasa desempleo llegaría al 9,7\%, el cual es equivalente a más de 9 millones de desempleados. Estos resultados demuestran con total claridad que los programas de ayuda financiera para salvar a los grandes bancos globales solo engrosan la riqueza de quienes las manejan, pero en nada favorece al sostenimiento y crecimiento de un sector tan crítico y volátil como es el del trabajo.

¿Y qué sucede en Europa, en especial España, que ahora ha visto comprometer su alicaída economía con la crisis Griega? Las estadísticas de la Organización para la Cooperación y el Desarrollo Económico (OCDE) señalan que el número de parados desde finales del 2007 al 2010 aumentarán en 2.706.000 personas. ¿Otro fracaso más del modelo neoclásico neoliberal?

En toda la zona de la OCDE el número de desempleados hasta junio del 2009 aumentó en casi 15 millones de personas y llegarían 25,487 millones hasta fines de 2010. Casi toda la población de Perú. Como dicen los analistas, en el 2010 se alcanzaría un nuevo récord en el campo laboral después de la Segunda Guerra Mundial, debido a que la cantidad de personas en los países industrializados, que no tendrían trabajo llegaría a los 57 millones.

A pesar que el gobierno de Estados Unidos y la zona del euro se han preocupado por estabilizar y fortalecer las cuentas macroeconómicas. La tasa de paro no da señales de revertir su tendencia, tal como señalan la cifras de la OCDE para el presente año el panorama laboral seguía volatilizándose, el cual es corroborado por el FMI. Ver Gráfico N 6.

La tasa de paro que está experimentando Estados Unidos no se podría considerar que es un fenómeno local, sino que sus efectos serán globales, esto es así ya que sus niveles de consumos se ajustarán a lo mínimo, lo cual significará que las empresas exportadoras de productos no tradicionales vean recortadas sus expectativas de ventas en ese mega mercado.

La caída del empleo en las principales economías del mundo se constituirá en un fenómeno negativo para las relaciones de los países en vías de desarrollo, que sustentan sus exportaciones en industrias que han sabido desarrollar fortalezas en su proceso de producción, por ejemplo las textiles, que en

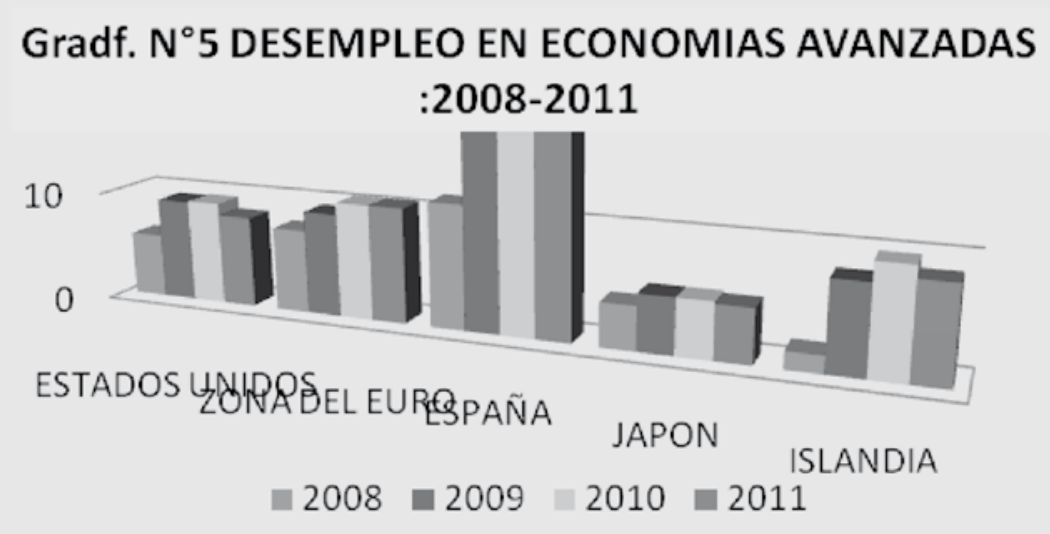

Fuente: FMI. Elaboración propia 
el caso de Perú, por la materia prima que utilizan y la especialización de la mano de obra, elaboran productos de elevada competitividad internacional, siendo sus principales mercados justamente los que están atravesando por una fuerte recesión.

\section{Participación de Latinoamérica en el flujo de capitales globales}

Como se ha evidenciado, los países industrializados están atravesando por una de las peores crisis en el mercado laboral, para corregir este desequilibrio no solo basta la aparición de los Estados otorgando salvavidas de última instancia, como lo han hecho casi todos los gobiernos afectados por la crisis, incluida la China, que dada la fuere inversión del estado está permitiendo que su PBI sea el más alto a nivel global. Si no que es importante las inversiones privadas, pero no aquellas que están dirigidas al mercado bursátil, ya que como se sabe buscan retornos inmediatos, a costa, inclusive, de poner en riesgo la estabilidad macroeconómica global, apuesten por colocar sus capitales en sectores estratégicos, creando puestos de trabajos sostenibles y reales, para este fin es necesario que las inversiones tengan la misma naturaleza, es decir que sean de largo plazo y que creen riqueza pero con responsabilidad social.
Dada la estabilidad macroeconómica de países de la región, como Chile, Perú, Brasil, éstos países se han constituido en destino importante para las inversiones productivas, especialmente en Brasil, que como se sabe se está constituyendo en una de las economías más importantes del mundo. En el caso de Perú, su principal socio de inversión se viene constituyendo Chile, ya que de los US\$ 1159 millones que este país invirtió en el primer semestre del 2009, Perú participó con el $58 \%$, equivalente a US\$ 678 millones, dirigidos especialmente a la industria agro exportadoras, financiera y de servicios. A la suma señalada hay que sumarle los US\$ 6525 millones que ya tenía invertido Chile en el Perú, resultados que se verán fortalecidos con nuevos tratados comerciales que se puedan establecer.

Chile, como producto de un prudente manejo de su política económica se ha convertido en un país exportador neto de capitales de largo plazo, la cual es efectivizada por grupos empresariales con capacidad de manejar capitales globales. Los inversionistas chilenos, han visto a Perú como una oportunidad para sus inversiones, porque existen espacios económicos que todavía se puede explotar y que poseen un perfil de alta rentabilidad, siendo una de ellas la agroindustria.

Si bien Argentina es el país que más ha captado capitales chilenos desde 1990, el cual llega cerca a los 16 mil millones de dó-

GRAFICO ${ }^{\circ}$ 6. CAPITALES EXPORTADOS POR CHILE A NIVEL REGIONAL: 2009 ( enero junio) (miles de millones de US\$)

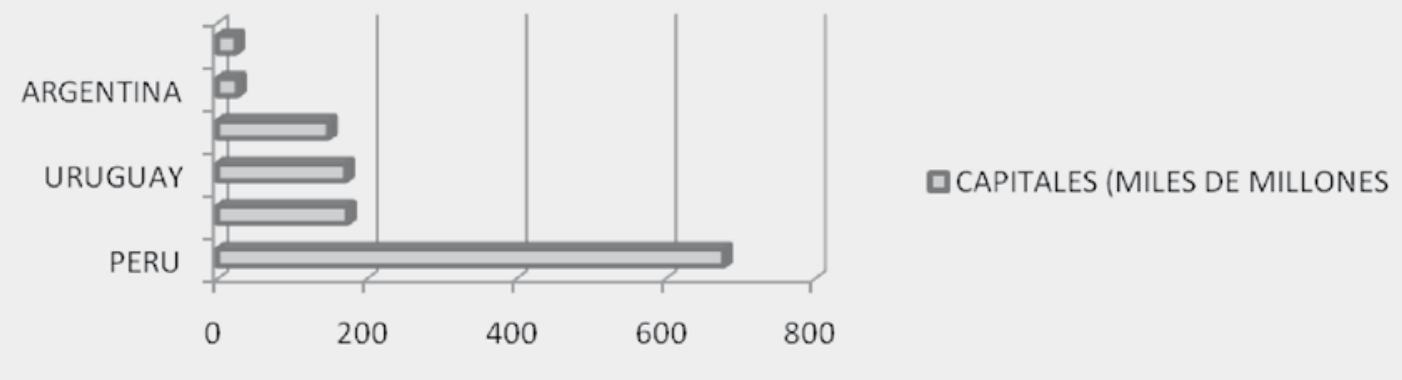

Fuentes: Gestión. 2010 
lares, pero Perú sigue la misma ruta estratégica y es muy posible que siga escalando posiciones hasta llegar en el primer lugar del ranking de inversiones a nivel regional. Una condición necesaria para este fin estratégico, es que mejore en el ranking de competitividad, especialmente en rubro de capacitación, capacidad gerencial, corrupción e infraestructura económica, que son las principales debilidades que presenta este país según el Informe de Competitividad Mundial (2010) de la escuela de negocios de Suiza Institute Managment Development.

Lo señalado anteriormente por cierto no muestra la tendencia de capitales en los mercados globales. Las asimetrías en el flujo de IED son importantes, los destinos de las grandes inversiones siguen siendo los países industrializados, quienes además reciben los usufructos de sus capitales que están sembrados a nivel global.

El hecho que el Perú, como otros países de la región, esté captando capitales chilenos, es una ventaja importante para fortalecer sus mercados internos, pero también es conveniente mencionar que la crisis global ha dejado huella en estos mercados. La confianza de los inversionistas se ha visto debilitada porque no tiene la seguridad que sus capitales invertidos tengan la rentabilidad que buscan. Esta actitud ha originado que en el 2008 las inversiones globales hayan retrocedido en un $14 \%$, el cual explica la retracción del flujo de inversiones en US\$ 282 mil millones.

La crisis global ha modificado la arquitectura financiera global, pero esto no implica que los países industrializados sigan siendo los grandes beneficiarios de estos flujos de dinero. El nuevo perfil de capitales dan una lectura de un avance importante de las economías en vías de desarrolladas como son las latinoamericanas, cuya participación en el flujo de capitales en el 2008 llegó al 43\%.
Bajo este escenario de crisis, los flujos de capital a Latinoamérica y el Caribe alcanzó la cifra récord de 107353.4 US\$ millones.

La volatilización de los mercados en el 2009 no solo golpeó a las economías avanzadas, sino también a las vías en desarrollo como son las latinoamericanas, países que recepcionaron IED por US\$ 76681 millones, cifra que implica una disminución del $42 \%$ respecto a lo logrado en el 2008. La caída fue diferenciada en esta parte de la región, siendo el país más perjudicado de este flujo de capitales Argentina, que experimentó una reducción del 50\% de capitales de largo plazo, seguido por Brasil con un 41\%. El impacto negativo también lo recibió el Perú ya que la llegada de capitales bajaron en un $31 \%$; a la luz de las cifras presentadas se afirma que la crisis global golpeó duramente a las economías latinoamericanas, pero a pesar de este "bache" financiera sus indicadores reales no sufrieron tanto daño como lo observado en las economías avanzadas. Algunos analistas llaman el "desenganche de las economías en vías de desarrollo" "a las volatilidades de las economías industrializadas.

Debido a la política que viene implementando el presidente Hugo Chávez en Venezuela, donde ha puesto en primera línea las confiscaciones y nacionalizaciones, según las cifras manejadas por la CEPAL, las IED bajaron de US\$ 349 millones logradas en el 2008 a una salida neta de US\$ 3105 millones en el 2009. Detrás de estas cifran están las grandes ETN que salieron de este país en resguardo de sus capitales invertidos, situación que ha llevado a Venezuela a un escenario de crisis interna.

La crisis económica golpeó con más fuerza en su epicentro: los países desarrollados. En 2009, la IED en estas economías cayó un $41 \%$ con respecto a 2008 y un $58 \%$ con respecto al 2007. En el caso de las economías en 


\section{Graf. N ${ }^{\circ} 7$ PARTICIPACION POR REGIONES EN LA ENTRADA DE CAPITALES : 2007-2009.estructura \%)}

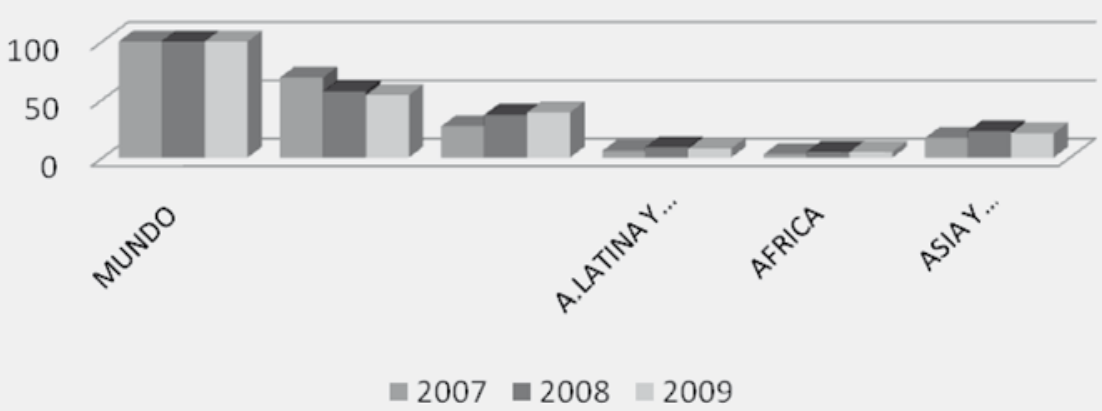

Fuente: CEPAL. Elaboración propia

desarrollo y transición, después de haber alcanzado su máximo histórico en 2008, la IED se redujo un $35 \%$ y un $39 \%$, respectivamente, en 2009. Como resultado, la participación de los países desarrollados en las corrientes globales de IED ha descendido del 69\% en 2007 al $57 \%$ en 2008 y al $54 \%$ en 2009 . En contraste, la participación de los países en desarrollo y transición ha aumentado de manera significativa, del $32 \%$ en 2007 al $44 \%$ en 2008 y al $46 \%$ en 2009 . Es probable que esta tendencia continúe durante 2010 en la medida en que las perspectivas de recuperación económica sean más altas en los países emergentes que en los países desarrollados. En 2009, los principales receptores de IED entre los paí- ses desarrollados fueron los Estados Unidos, Francia, los Países Bajos, Alemania y Bélgica, mientras que entre los países en desarrollo se destacaron China, Hong Kong (Región Administrativa Especial de China), la Federación de Rusia, la India y el Brasil.

Como se ha señalado, este nueva arquitectura financiera internacional, donde se ha visto un notorio avance de las economías en desarrollo, los países industrializados siguen captando la mayor cantidad de capitales que se mueven a nivel global, asimetría que es más notoria si se compara con las economías latinoamericanas cuya participación en el flujo de inversiones no llega al 10\%, tal como aprecia en el Gráfico $\mathrm{N}^{\circ} 8$ y 9.

\section{GRAF. $N^{\circ} 8^{\circ}$ RECEPCION DE IED POR REGIONES ( Miles de millones de US\$)}

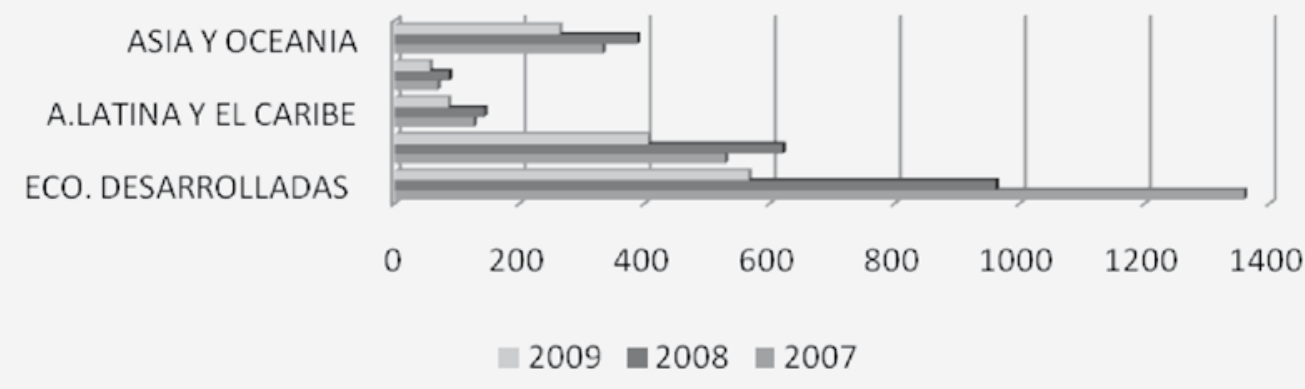

Fuente: CEPAL. Elaboración propia 
GRAF. N 9. IED POR PAISES LATINOAMERICANOS:200-2009 ( Miles de millones de US\$)

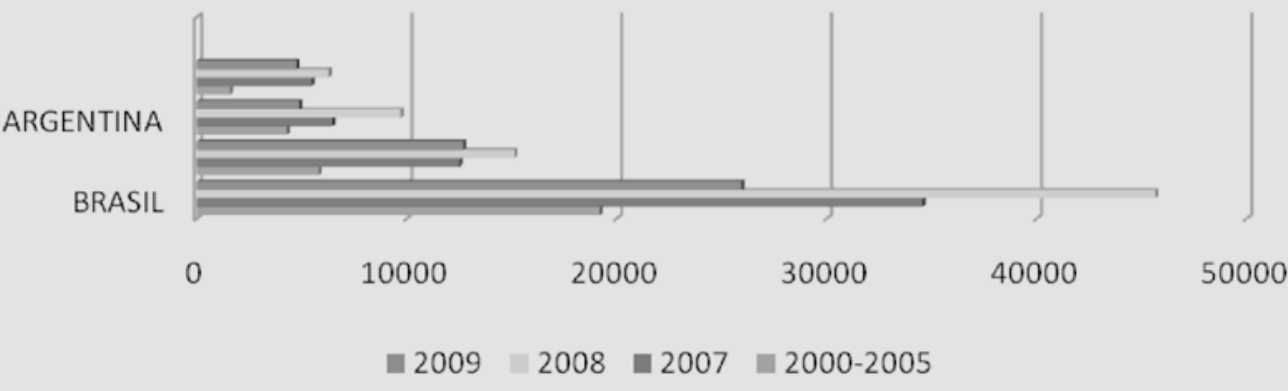

Fuente: CEPAL. Elaboración propia

Perú, debido a los cambios estructurales que ha tenido en los últimos 20 años, también está participando significativamente en este flujo de capitales, pero todavía la recepción es muy incipiente en comparación a las necesidades de inversión que necesita para potenciar su aparato productivo. Brasil capta el $48 \%$ de las IED que llegan a Latinoamérica, Chile participa con el $23.3 \%$, a diferencia de Perú, que solo participa con el $8.7 \%$. Resultados que se aprecia en el Gráfico N. ${ }^{\circ} 9$.

\section{ECONOMÍA LATINOAMERICANA: SECTOR REAL Y FINANCIERO BAJO LA CRISIS GLOBAL}

Las economías latinoamericanas, como es el caso de Perú, están enganchadas al comportamiento de las economías industrializadas, su grado de dependencia llega a tal nivel, que si la economía mundial llega a volatilizarse, inmediatamente la región sentirá los efectos del impacto, especialmente el sector productivo. Como se conoce las economías de esta región, con excepción de Brasil, se han especializado en la exportación de productos tradicionales, que es la principal fuente de generación de divisas y de recaudación tributaria de sus respectivos gobiernos.
La tecnificación de su aparto productivo es muy incipiente, en estos países no se han desarrollado medios tecnológicos que les permitan potenciar al máximo sus capacidades productivas y ser exportadores netos de capital, tanto real y financiero.

Cuando los mercados se volatilizan y tienden a la baja, por la alta correlación que existe, se exporta menos, los tipos de cambio llegan apreciarse, se reducen las fuentes de empleo, baja la presión tributaria, en sí, aparecen una serie de síntomas perniciosos para las economías dependientes.

El grado de dependencia se puede apreciar mediante el comportamiento del PBI, en los meses de crisis del 2009, como es el caso peruano, esta variable sufrió una caída importante llegando a mostrar señales de recesión, si bien no se experimentó la tasa de desempleo, como lo observado en la Zona del Euro y Estados Unidos, pero si golpeó más que todo a la industria exportadora como es la textily minera.

Se trata de economías emergentes, si bien la crisis también llegó a estas economías, ya que Estados Unidos representa uno de los principales mercados para la China y la India, pero la caída del PBI, no fue tan significativa, gracias a la agresiva participación de sus gobiernos y las políticas de comercio exterior 


\section{Graf. N 10. PBI ECONOMIA DE AMERICA:2008-2011}

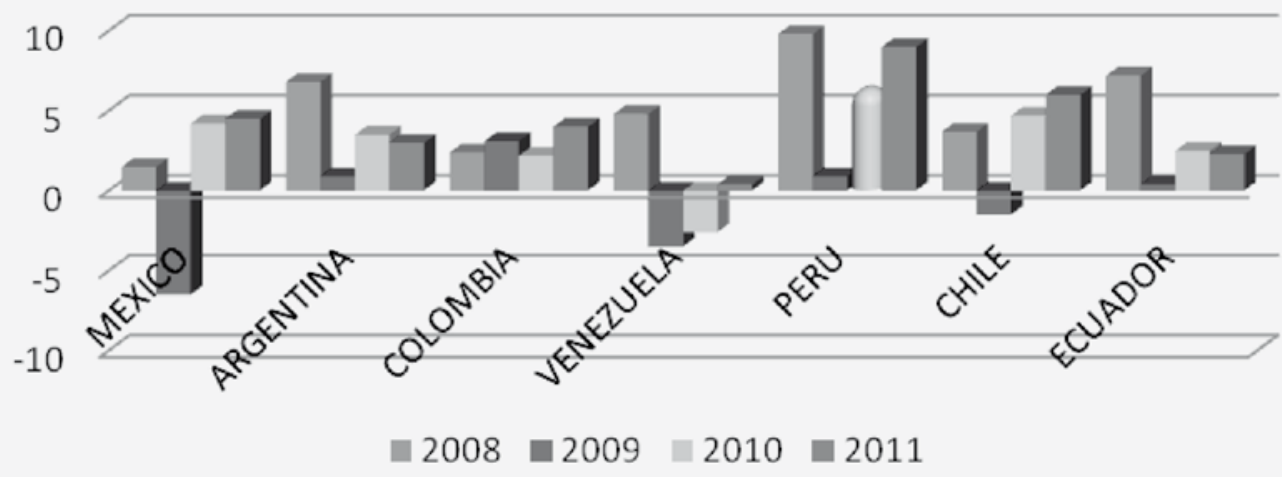

Fuente: FMI. Elaboración propia

que poseen estas economías, que apuestan por la diversificación con generación de valor agregado.

La China y la India de seguir con esta tendencia, en un futuro serán las que más aporten a la riqueza mundial, pero podría aparecer un riesgo que podría desequilibrar el panorama económico global, el cual sería la inflación global, sustentada en un consumo que pondría en peligro la seguridad alimentaria de todo el Planeta. Si bien el PBI mundial en época de crisis no alcanzó una cifra negativa, fue gracias a la participación de las economías emergentes y en cierta forma también al PBI logrado por las economías latinoamericanas.

Para el logro de estos indicadores si bien jugó un papel importante la participación del gobierno, política keynesiana típica, pero también fue importante la implementación de políticas monetarias contra cíclicas que ayudó a expandir la liquidez del mercado monetario, que a la vez fue complementada por la tasa de política monetaria. Con el amortiguamiento de la demanda agregada, el PBI siguió la misma tendencia, que en definitiva fue favorable para los países latinoamericanos, cuyas exportaciones de materias primas tienen este mercado de destino. Con un mercado financiero más estable y con la preferencia de las ETN para invertir en estos mercados, la China es posible que alcance el crecimiento económico más alto a nivel global, mas no así un desarrollo social sostenido.

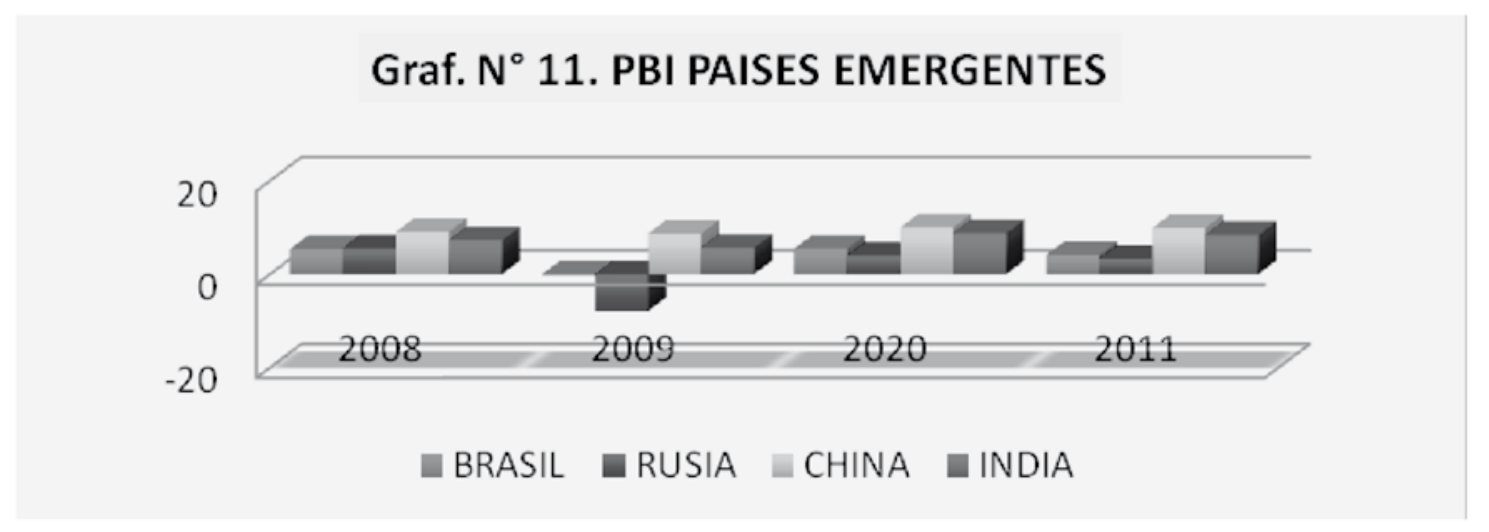

Fuente: Banco Mundial. Elaboración propia 
Tal como presenta el FMI en su informe "Perspectivas de la economía mundial 2010", Las autoridades se enfrentan a arduos retos. En muchas economías avanzadas y en una serie de economías emergentes, deben reequilibrar la demanda para depender menos del sector público y más del sector privado, y al mismo tiempo sanear las finanzas públicas y el sector financiero.

Por otro lado, es conveniente señalar que, los bancos de los países industrializados, especialmente los norteamericanos, son los que tienen el control de los hilos financieros del mundo, a pesar que han tenido tropiezos de envergadura por la crisis internacional y hayan contagiado sus cuentas con activos tóxicos, siguen manteniendo importantes patrimonios, en comparación con la banca latinoamericana. Bank of América, JP Morgan, Goldman Sachs y Morgan Stanley, Merry Lynch, Wells Fargo son entidades financieras, que en cierta forma fueron los que propiciaron la crisis, pero siguen teniendo la hegemonía económica en este mundo global.

Grafico N. ${ }^{\circ} 11$. Créditos reales de las EFI en Latinoamérica.

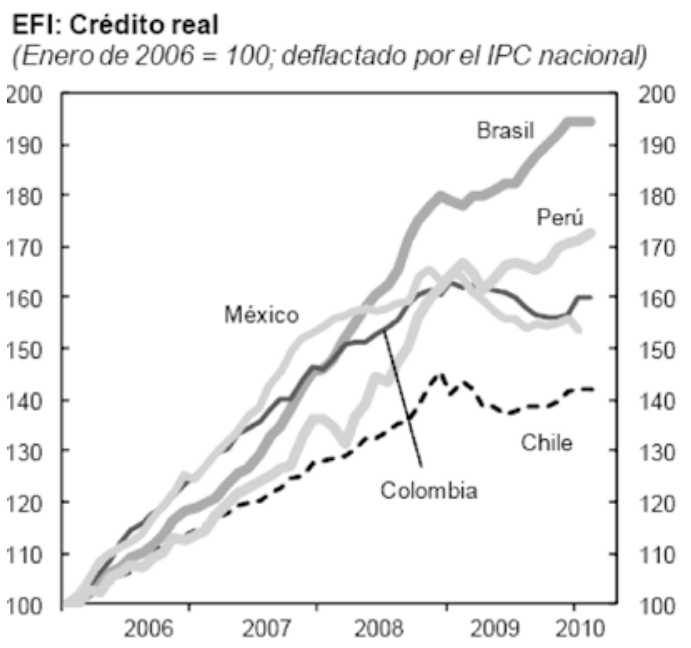

ALC: Crédito de bancos extranjeros

(Variación porcentual anual en valor en dólares de EE.UU.)

Fuente: FMI
Contrario a lo sucedido en esta parte del mundo, en Latinoamerica el impacto de la crisis fue mucho más tolerante, los bancos mantuvieron sus carteras controladas y no se vio la quiebra de algún banco importante que introdujera nerviosismo en el sector. Bancos como Santander Santiago, Pichincha, de crédito, BBVA de chile, Banco Colombia entre otros, siguen operando con las fortalezas que los caracteriza, no en vano están en el ranking de los 25 mejores bancos de Latinoamérica, la clave para la solidez de la banca en Latinoamérica fue la supervisión y el control a los movimientos bancarios, elemento clave que carece la banca internacional.

Los créditos bancarios a nivel de la región se están normalizando, si bien en plena crisis no tuvieron una reducción importante, ya que sus cuentas de riesgo estuvieron adecuadamente monitoreadas, actualmente con la estabilización de los mercados, han vuelto a su tendencia normal. Cabe destacar que la banca jugó un papel importante en el amortiguamiento de la crisis, debido a que los créditos concedidos a personas naturales y empresas mantuvieron la demanda agregada y con ellos sostuvieron la caída del PBI.

El FMI ha manifestado que los países exportadores de materias primas tendrían un crecimiento más rápido el presente año, tales como Perú y Chile, países que sustentan su comercio exterior y su generación de divisas con exportación de minerales. Además sostiene que aumentarán sus RIN con sus cuentas fiscales, pero este escenario podría tener brechas de vulnerabilidad si es que aparece una nueva ola de crisis global, o en todo caso si la crisis Griega, conjuntamente con la de Portugal y España tiende a magnificarse.

Al reactivarse, aunque lentamente, la economía, los precios de las materias primas seguirán alcanzando cifras mayores, es por ello que el FMI estima que el 2009 se revertirá el comportamiento vengativo de las exporta- 


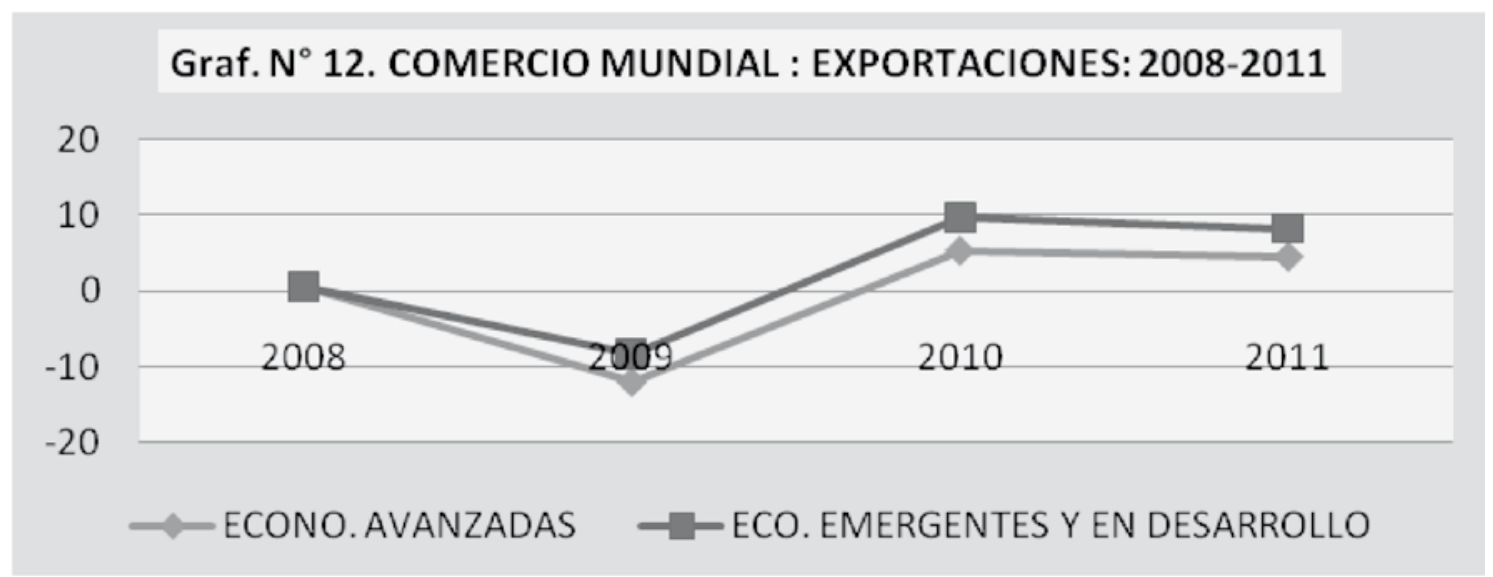

Fuente: FMI. Elaboración propia

ciones de Latinoamérica. Otra evidencia más de la dependencia de la región al avance de las economías industrializadas.

Si bien estos últimos países tienen poca relación con Latinoamérica pero el mecanismo de transmisor estaría por la economía norteamericana y la zona del euro, que como se conoce ha sufrido al retroceso del euro. Las volatilidades en los mercados están presentes, pero para evitar los impactos, las economías latinoamericanas tienen que blindarse con políticas inteligentes, estructurales y de largo plazo.

\section{CONCLUSIONES}

Las economías industrializadas a pesar de haber experimentado una fuerte crisis económica y financiera continúan manteniendo su hegemonía global, por lo que cualquier volatilidad que se presente en sus cuentas macroeconomías se transmitirá rápidamente a las economías de la región.

La hegemonía económica de los países industrializados ha originado que se presenten brechas estructurales entre estas economías y las de vías en desarrollo, los cuales se operativizan a través de los mecanismos redistributivos, ingresos percápitas, capitales de exportación, entre otros.
La asimetría que se observa a nivel global no solo se plasma en el tipo de empresas transfronterizas, sino tambien en los niveles de riqueza personal, que supera inclusive al PBI de economías pobres. Esta asimetría redistributiva se ha profundizado con la globalización.

Las economías de Latinoamérica, con esta última crisis, han dado señales de un cierto desprendimiento de las economías del primer mundo, pero esta fortaleza que está apareciendo aún es débil, sabiendo que esta mejor posición más que todo se debe al desarrollo de sus ventajas comparativas. La asimetría es ventajosa para las encomías industrializadas que sustentan su poder económico con ventajas competitivas en todos los niveles económicos y financieros.

Para revertir los escenarios de crisis los gobiernos de los países industrializados están aplicando medidas que no encajan dentro del modelo neoliberal, el cual es la intervención del Estado en asuntos económicos. La intervención gubernamental, propia a una política keynesiana ha conllevado a aplicar políticas de subsidios a bancos quebrados. Mientras se habla de billones de dólares para la compra de activos tóxicos, en el mundo pobre se habla de vivir con menos de un dólar por día. Asimetría estructural que no se resolverá bajo un modelo de globalización. 
Se vislumbra que los países emergentes se irán fortaleciendo a nivel global, desplazando a las economías del primer mundo, esta situación podría representar un serio peligro para la seguridad alimentaria del mundo. Pero es una oportunidad para que las economías latinoamericanas sigan exportando sus materias primas.

\section{RECOMENDACIONES}

Las economías en desarrollo deben de aplicar políticas para que en todos sus sectores productivos se desarrollen las ventajas competitivas, lo cual implicaría realizar investigaciones, innovaciones, mejora sostenida de procesos, situación que les conllevaría a un rápido "desenganche" de las economías industrializadas, reduciéndose así los impactos de la volatilización de los mercados globales. Para el logro de este objetivo es necesaria la participación del Estado, la comunidad empresarial y la académica. La inyección de una nueva filosofía de gobierno debe encuadrarse dentro de una política redistributiva equilibrada y en dejar de lado el principio básico de los mercados, que solo tienden a crear actitudes especulativas

Las economías latinoamericanas deben de aplicar políticas conjuntas pensando en bienestar regional, ya que bajo un escenario de globalización, el bienestar unilateral debe dar paso al bienestar conjunto. Si se logra mejores indicadores de desarrollo para la región se convertiría en un escenario propicio para las inversiones globales. Las políticas fiscales y monetarias deben tener la característica de global, de tal forma que permita el crecimiento simétrico y se forme además un escudo económico a las volatilidades que se presentan en las economías industrializadas.

Los gobiernos de las economías latinoamericanas deben ejercer mayor control al movimiento de capitales especulativos de los países industrializados, que como son de corto plazo vulneran la estabilidad del mercado monetario y cambiario, afectando asa los procesos de crecimiento. El control de estos flujos financieros internacionales deben ser a nivel de la región, ya que de por medio está la estabilidad regional y con ello se manejaría con mayor eficacia el riesgo región.

Las economías latinoamericanas, bajo el trabajo conjunto entre empresas y gobierno, deben aplicar políticas que les conlleve a diversificar sus mercados de exportación, y así ser menos sensibles a los vaivenes de las economías industrializadas. Los nuevos países emergentes podrían ser una óptima oportunidad para el fortalecimiento del comercio internacional, no solo para exportar materias primas sino para desarrollar la industria exportadora, para ello se necesita capitales reales e inversionistas con responsabilidad social.

\section{REFERENCIAS BIBLIOGRÁFICAS}

1. Fondo Monetario Internacional (FMI). "Perspectivas de la economía mundial". Junio del 2010.

2. Fondo Monetario Internacional (FMI) . "Informe sobre la estabilidad financiera mundial”. Junio del 2010.

3. Fondo Monetario Internacional (FMI). "Perspectivas Económicas: las Américas". Junio del 2010.

4. Banco Mundial "Informe sobre el desarrollo mundial 2010” -. WDC 2010.

5. Banco Mundial "Análisis del Riesgo Bancario, 2010". WDC 2010.

6. CEPAL "Estudio Económico para América Latina”: 2009-2010 - WDC.

1. Banco central de Reserva del Perú: Estadísticas Mensuales: 2010.

2. Diario Gestión: Varios números: Lima Perú. 